\title{
ROLE OF STAKEHOLDERS AT CAPE COAST PPAG YOUTH CENTRE: DEFICIENCIES AND IMPLICATIONS.
}

\author{
BADU, Kwaku Gyasi \\ Faculty of Education \\ University of Cape Coast \\ Ghana \\ email: asamoagyima@yahoo.com
}

\begin{abstract}
The study investigated whether the activities or the roles performed by the various stakeholders at the Cape Coast Planned Parenthood Association of Ghana (PPAG) youth centre impacted positively on the youth behaviour and performance at the centre. The sample comprised 22 teachers, 50 parents and 3 social welfare workers who were supposed to work with the centre. Data was collected with questionnaire and analysed with percentages. The results indicated that apart from the seemingly impressive recommendation role of stakeholders, all the other roles, namely, information, visitation, referral and follow-ups were found to be weak and ineffective and seemed to have little impact on the youth and the programme in general. It is recommended among others that long term educational campaign programmes should be mounted for all stakeholders on a regular and sustainable basis to achieve this desired goal.
\end{abstract}

Key Words: stakeholders, youth, deficiency, quality care delivery, education.

\section{Introduction}

The Bruce-Jam framework of perception of quality care delivery talks about interpersonal relationship, quality of information and technical competence of providers as factors which people perceived to influence quality care delivery of any given programme. The social theory of perception has it that people tend to be attracted to those who appear capable, knowledgeable and intelligent as opposed to those who are not (Davies \& Houghton, 1991). The implication of the above assertion is that one needs to gather people who are capable, knowledgeable and intelligent to handle individuals and groups of people at any given time. Family Life Education (FLE) service, like all other services, is multidimensional and therefore requires the efforts of all stakeholders to make it a success (Connolly, 1992). Stakeholders are partners in 
development and as such work together to produce results in any given programme. The Planned Parenthood Association of Ghana (PPAG) is one of the main organizations responsible for the organization of FLE services in the country. Other stakeholders for FLE services in the country include: teachers, parents, social welfare workers and pastors. This means that the PPAG officials, together with these partners, constitute stakeholders who have parts to play in the promotion of FLE services as well as quality care delivery for the youth (Lloyd and Ann, 1996).

The roles of FLE stakeholders are many. Generally, they have complementary roles to play in the promotion and achievement of organisational goals. Specifically, they are supposed to have ample knowledge about the organisations (services/programmes), which they are key partners. They should be able to brief people on the aims and objectives of the organisations and the specific activities performed by such agencies. At the same time, stakeholders should have adequate knowledge about the strengths and weaknesses of the organisations. They should also find out the reasons that account for high or low patronage of services by clients.

Firstly and specifically, stakeholders recommend services to their clients. They recommend to various clients opportunities that are available to them in a specific organisation. Secondly, they are also supposed to visit the service centres to acquaint themselves with the developments taking place at the Centre. It also affords them the opportunity to encourage both service providers and clients. The visits also give them the opportunity to lend their support to the organisations as they come face to face with the problems confronting the organisations. Thirdly, the stakeholders refer cases that are beyond their control for proper redress. They may not have adequate knowledge and facilities to deal with certain situations or problems and therefore there is the need for such cases to be referred to appropriate quarters for redress. Fourthly, stakeholders are also obliged to follow-up cases they have referred to certain centres/agencies for an update. Referral of cases without corresponding follow-ups will amount to fruitless efforts. Follow-ups are meant to monitor the extent to which the client (s) referred is/are performing and to find out ways of assisting them.

The Cape Coast PPAG youth centre, realizing the immense contributions of stakeholders as well as their own limitations in dealing with the complex problems of the youth, has joined hands with these groups to manage the centre. They include teachers, parents and social welfare workers. The teachers are either Patrons or Assistant Patrons of the Family Life Education Club (FLEC) in the schools and thus serve as 
co-ordinators between the youth and the youth centre. The parents also provide some useful information about their children and wards for use by the centre. The social welfare workers also, by nature of their work, work in close collaboration with the youth centre to promote their welfare. To date, there appears to be no formal research work done in this area to assess the impact of the role of stakeholders on their activities at the youth centre.

\section{Purpose of Study}

The purpose of this study was to examine the roles played by the stakeholders and to determine whether it had any significant impact on the lives of the youth or contributed to quality care delivery at the centre. The following questions were raised to guide the study:

- To what degree are the stakeholders carrying out their functions in order to meet the quality care delivery which the centre so much desires?

- Are they able to impact positively on the behaviour and performance of the youth at the centre?

\section{Method}

\section{Participants}

Participants were made up of 49 male and 26 female stakeholders working with the Cape Coast PPAG youth centre. Ages of the participants ranged from 20-59 years. Out of this number, (22) were teachers, (50) parents and (3) social welfare workers.

\section{Instrument}

The measuring instrument was a 25-item and 23-item questionnaire designed for teachers, parents and social welfare workers. The instrument was validated on the basis of relevant literature review, expert advice and adoption of an instrument with high internal consistency reliability. The instrument yielded correlation co-efficient reliability of $\mathrm{r}=0.90$.

\section{Procedure}

Purposive sampling technique was employed to select the stakeholders. Three schedule officers (Social welfare workers) as well as selected parents of committed FLEC members and teachers who were either patrons or assistant patrons were included in the study. With the exception of teachers whose response rate was $88 \%$, the rest were $100 \%$. 
The questionnaires were administered by the researcher. Percentages were the main statistical tool used.

\section{Results}

The purpose of the study was to find out whether the stakeholders performed their roles as expected. It also sought to find out whether their roles had any significant impact on the lives of the youth as well as the centre. The study shows that both clients (youth) and service providers (PPAG staff) do not enjoy any remarkable satisfaction from the services of the stakeholders. The actual roles performed by the stakeholders fall short of the roles expected of them as development partners to push the activities at the youth centre forward

Table I Distribution of Stakeholders by Their Roles at the Centre

\begin{tabular}{|l|c|c|c|}
\hline Roles & $\begin{array}{c}\text { Teachers } \\
\text { Percentage }\end{array}$ & $\begin{array}{c}\text { Parents } \\
\text { Percentage }\end{array}$ & $\begin{array}{c}\text { Social Welfare } \\
\text { Percentage }\end{array}$ \\
(A) Information & 100 & 62 & 100 \\
- Awareness & 59.1 & 38 & 100 \\
- Knowledge & 13.3 & 8 & - \\
- Assessment & 100 & 76 & 100 \\
(B) Recommendation & 40.9 & 38 & - \\
(C) Visitation & - & 8 & - \\
(D) Referral & - & 4 & - \\
(E) Follow-ups & Teachers = 22; & Parents = 50; & Social Welfare Workers $=3$ \\
\multicolumn{2}{|c|}{ Tource: Fieldwork, 2002 }
\end{tabular}

Information giving constitutes one of the roles of stakeholders in their dealing with the agencies and clients that they serve. Without proper and concise information clients cannot take advantage of even well managed services for any specific target group. It is, therefore imperative that this tool be made to work effectively to meet the aspirations of clients and service providers in the search of quality care delivery. This section, therefore, focuses on how information flow contributed to quality care delivery at the centre. With respect to awareness of the youth centre, all the twenty-two teachers interviewed indicated that they were aware of the existence of PPAG youth centre at Cape Coast. However, 38 percent of the parents revealed that they were 
not aware of the existence of the centre. Again, all the social welfare respondents indicated that they were aware of the existence of the centre.

Closely linked to the awareness of the centre by the stakeholders, is the knowledge of services provided by the youth centre. About 59.1 and 38 percent of the teachers and parents respectively and the entire social welfare workers stated that they had knowledge about organisations such as, PPAG, churches and schools, providing FLE services for the youth. At the same time, nearly 41 percent of teachers knew that Cape Coast youth centre provided library, counselling, clinical and family planning services for the youth. They also knew that film and talk shows, were used to educate the youth on family life issues.

With regard to amount of information they have on FLE issues at the centre, the stakeholders were found to be performing at different levels. On general assessment of FLE issues, thus, services rendered at the centre, 13.3 and 8.0 percent of the teachers and parents respectively were able to assess the service centre. On the other hand, 76.7 and 92 percent of respondents (teachers and parents respectively) could not assess the service. Furthermore, 45.5 percent of respondents (teachers) were able to assign reasons for youth patronage at the centre. Out of this, 27.3, 13.6 and 4.6 percent of respondents indicated 'socialisation', 'interaction' and 'counselling' respectively as the main reasons for youth patronage of the centre.

Some 24 and 14 percent of respondents (parents) saw 'curiosity' and 'exchange of ideas' respectively as the main reasons for the youth patronising the centre. Pertaining to reasons for not patronising the centre, 54.5 percent of the teachers indicated various reasons for the development, including shyness (18.2\%) ignorance $(18.2 \%)$ and heavy schedule $(13.6 \%)$. About 45 percent of teachers and 24 percent of parents were also able to identify differences between Family Life Education Club (FLEC) members and Non-FLEC members. They had this to say: "They tend to be more responsible and neat". "They relate better to the opposite sex than non-members" and "Their relationships with their families have improved".

The role of stakeholders in information delivery at the centre seems to indicate that the stakeholders are performing at the barest minimum. It could be said, however, that in terms of awareness of the centre, the stakeholders (teachers and social welfare workers) seem to know about the centre. These results are all presented in Table I.

The above scenario could be explained by the fact that the stakeholders apart from complementing the efforts of the PPAG officials 
in providing FLE services for the youth engage themselves in their formal duties. This means that they consider this task as extra duty and therefore take less of their time. This position is defensible, in that, it makes sense for one to concentrate largely on formal duties assigned to him or her and less time on informal duties.

The weak knowledge base and participation of parents, in particular, is understandable. Unlike teachers and social welfare workers, which officially have been charged with the management of youth problems by the state, parents unofficially take charge of the youth and this might explain why they have not been able to give off their best as compared to teachers and social welfare workers.

\section{Recommendation to the Centre}

Recommending and directing people to where they could seek assistance contribute immensely to solving the problems of those individuals concerned and also help to promote quality care delivery as a result of good guidance. The objective here is to look at how stakeholders at the Centre used this means to achieve quality care delivery for the youth. Development partners of FLE services at the Cape Coast PPAG youth centre have in diverse ways managed to recommend and expose youth to activities and programmes at the youth centre in Cape Coast. A study conducted by (Badu, 2006) on the youth indicates that through the efforts of FLE stakeholders, some of the youth got to know about the activities at the Cape Coast youth centre. Both the participants and non-participants revealed that one of the ways they got to know about the activities of PPAG FLE services at the Cape Coast youth centre was through community leaders such as teachers, parents, pastors and social welfare workers. About 17 percent of youth reported that they got to know the message through the entire efforts of these community leaders. In the same vein, the social welfare respondents indicated that they recommended FLE services to the youth "to enable them have the chance to grow to become responsible adults". Similarly, 76 percent of parents showed that they recommended FLE activities to the youth so that "they would lead decent lives". About 46 percent of teachers who responded to the issue of recommending FLE issues to the youth stated that they had recommended FLE services to the youth so that they "could take advantage of the services at the centre". The other 54.5 percent of the respondents revealed that they had recommended the services to the youth "to enable them acquire knowledge about adolescent reproductive health". In all, the respondents responded favourably to the issues. 
From all indications, it could be said that the stakeholders of FLE services had at various instances found it necessary to recommend or approve FLE services to the youth. This is evident in the declaration of the stakeholders with respect to this particular task. However, there is some concern since only 17 percent of youth got to know the centre through the core stakeholders. It means that a large number of youth got to know the centre through other means. (Badu, 2006). This not withstanding, the data suggest that the stakeholders are aware of the importance of FLE services. They know that this service could impact positively on the general well being of the youth.

\section{Visitations to the Centre}

Visitations in every form boost the morale and serve as encouragement to those visited and therefore partly solve the problems that they may have. This section focuses on how various stakeholders applied this means to promote quality care delivery at the youth centre. There was a general consensus by the stakeholders that visitations to the Cape Coast PPAG youth centre were very poor and ineffective. The data indicated that visitations to the youth centre were very poor. Indeed, about 41 percent of teachers had visited the youth centre as compared to 38 percent of parents. The social welfare workers had not visited the centre at all. Again, all the respondents could not indicate the number of times they had visited the centre and this supported the fact that the visitations to the centre were very few.

\section{Referrals to the Centre}

Referring clients to PPAG youth centre is as important as visiting the youth centre. The results of the study on referring cases to the Cape Coast youth centre by core stakeholders (teachers, parents and social welfare workers) indicated that referrals to the centre were not encouraging.

It was established that all the teachers and the social welfare workers had not referred cases to the Cape Coast youth centre. Similarly, 92 percent of parents had not referred cases to the youth centre. The data above indicate that the referral roles of the various stakeholders have been very disappointing and suggest lack of enthusiasm and commitment on the part of the stakeholders. It further implies that the stakeholders seem to lack knowledge about the principles of referrals. 


\section{Follow-ups to the Centre}

Follow-ups are necessary ingredients to ensure that the problems of clients are resolved. This part of the study attempts to look at how effectively the stakeholders used this technique to advance the course of quality care delivery at the centre.

Closely linked to the referral role of stakeholders are the follow-up activities of stakeholders. The analysis of the data on stakeholders' activities at the Cape Coast youth centre revealed that 100 percent of teachers who were either Patrons or Assistant Patrons of FLEC had not done any follow-up to the youth centre. Similarly, the social welfare workers had not done any follow-up to the centre at all. However, 8 percent of parents had followed up cases referred to the centre. When pressed to know the outcomes of such follow-ups, they simply remarked, "it was very good".

The data seem to suggest that the follow-up exercises on referral cases to the youth centre are very poor and discouraging. Not only that, it also shows the weak commitment on the part of the stakeholders so far as FLE activities at the centre is concerned. The finding is also consistent with the weak referral cases recorded by the study, and thereby seems to make the claim more credible.

\section{Discussion}

The results of the study have so far shown that apart from the recommendation role, which the stakeholders seemed to perform creditably, they performed abysmally in all the other areas, namely information, visitation, referral and follow-ups and therefore fell short of the quality care delivery they were supposed to deliver.

The issue of a seemingly high recommendation role performed by the stakeholders at the centre has also been established by other research findings. Nkandawire and Mataya (1985) have observed that recommending services to clients was not a problem to many stakeholders. They contend that it was one of the easiest tasks to be performed among all the other roles in a bid to promote clients' participation and involvement in any service delivery or programme. They, therefore, proposed that regular and timely workshops should be organised for all stakeholders to enlighten them on the need to intensify their efforts to make more people aware of available services.

Thus, the outcome of the research findings so far discussed is in line with what the stakeholders ought to do with respect to their recommendation role. What is needed is to strengthen this position by constantly organising educative but inspiring messages for the 
stakeholders to update their competence and give off their best in this area. It should be pointed out that it is a duty, which they have to fulfil for the overall development of our youth. Furthermore, this development or position is in line with natural law of passing on good deeds or culture to the succeeding generation. The import of this position is that no matter the cost, humans would like to hand over the good deeds to their children or successors to enable them enjoy the best of life. It also supports the view that in contemporary times, parents recommend good education or services for their children/wards to enable them realise the huge investments made in them. Above all, it could be deduced from the data that the level of participation of youth in FLE activities in the Cape Coast municipality is partly as a result of the recommendation role of the stakeholders.

The indifferent attitudes of some stakeholders coupled with their limited knowledge about the activities of service providing agencies, in no small way, contributed to the minimal impact of FLE services on the youth in Ghana (Nkandawire and Mataya, 1985). The outcome of this study has also supported this assertion. Stakeholders at the Cape Coast PPAG youth centre seemed to perform poorly so far as knowledge and services of PPAG activities at the youth centre were concerned. The study further indicated that the response rate about the activities of the youth centre was very low. Where responses were even indicated, the information provided was scanty and suggested that they seemed to lack the basic knowledge about the services at the centre.

The issue here is how to get the stakeholders to be abreast with the events and activities taking place at the youth centre. Perhaps there is the need to mount well-planned strategy to reverse this trend. A programme for all stakeholders should be mounted either by the agencies for stakeholders or through the various mass media to educate the stakeholders on their responsibilities. Finally, this development is in line with the general attitude of people when it comes to performing a task. The general notion that their services will go unnoticed coupled with low incentives and motivation all contribute immensely to poor performance in such matters.

The study also shows that teachers, parents and social welfare workers hardly visited the centre. The poor visitation role by all the stakeholders at the Cape Coast PPAG youth centre has also been reported by Glover, Enilkar, Nerquaye-Tetteh (1998) who observe that visitations to some youth centres in Ghana by both youth and other stakeholders 
were not encouraging and therefore needed a concerted effort of all to reverse the trend in order to benefit the youth.

The above findings also bring to mind one main issue, which is that of responsibility. As stakeholders they do not think that they have to visit the centre as expected of them. They think that it is the responsibility of the clients, whose interest they are serving. After all, it is the clients they are trying to help respond to behavioural change and, as such, it is their responsibility to visit the centre regularly. Unfortunately, this is not the case for even the youth who are participants of FLE services. This means that the problem of visitation is an issue for both the clients (youth) and the stakeholders. Some of the youth may take advantage of the stakeholders' poor visitations to the centre to absent themselves from FLE schedule meetings and activities on regular basis.

The poor visitation at the centre could also be partly explained by the heavy schedule of duties on the part of some stakeholders. In a developing country such as Ghana, people apart from their official work may be involved in other economic ventures or other social ventures, such as, family matters, church activities and other social activities to make life worthwhile and meaningful. This obviously, will have a negative impact on their visitation roles.

The poor visitation at the centre could be attributed to the location and opening hours of the centre. The stakeholders being workers would find it difficult to visit the centre during the weekdays considering the location of the centre, which is a little bit far from the town centre. This fact was supported by the youth (participants and non-participants) who expressed the need for the centre to be open late in the evenings and then on weekends to make way for them to participate effectively (Badu, 2006).

Furthermore, the poor visitation 'has a close relationship with youth delinquencies as a result of lack of proper guidance. The finding is also in line with the clarion call on all Ghanaians to join hands to train and educate our youth in a more satisfactory manner through individual and co-operative support. Finally the finding is also consistent with human nature. It is in line with the old adage that says, "it is easier said than done". Many people would like to speak forcefully on issues but when it comes to implementation they are found wanting. This attitude cuts across all facet of life. Normally, people think or assume that all are well and therefore find it difficult to visit places or people to offer their support and advice.

The weak and ineffective referral roles by stakeholders at the Cape Coast PPAG youth centre are not different from other research findings 
(Connolly, 1992) has observed that referring cases to the youth centres by the various stakeholders continues to be one of the major setbacks in the overall achievement of FLE goals for the youth. He suggests that a wellplanned programme on a regular sustainable basis should be organised for all stakeholders on the philosophy behind referral of cases.

The finding is also consistent with people's difficulty in referring cases to appropriate sources where necessary. It is generally accepted by people that referring cases to others means "limitation" or "failure" to deal with the situation and therefore may hang on even in the face of total hopelessness. This development is against the principles and philosophy of "referrals" in guidance and counselling and even in general educational psychology. It is expected that cases that service providers have little expertise should be referred to experts who have the expertise and ability to deal with them in a very satisfactory manner. This principle explains partly why teachers, (stakeholders of FEE services at the centre) failed to refer cases to the centre. As teachers, and of course, as Patrons or Assistant Patrons, they have basic knowledge about FLE activities and therefore think that they can deal with the cases without reference to the youth centre. The same could be said about the parents and social welfare outfit as they also consider themselves capable of handling youth problems. Again, the weak referral cases to the youth centre may also be partly responsible for the high incidence of indiscipline in recent times, especially, in matters related to responsible sexual life.

The findings also could be explained in part by the attitude of youth trying to solve most of their problems on their own. Most youth think that they are adults and therefore can deal with their problems effectively. This attitude may not encourage adults (stakeholders) to refer them to appropriate quarters for assistance. This point is supported by educational psychology principles of adolescent stress and storm, which posit that adolescents find themselves in their own world, and think that they are mature and can solve their own problems (Fobih, 1993).

The research findings also established that with the exception of a few cases, the stakeholders never followed-up cases referred to the centre. These findings are similar to observations made by Glover, Erulkar, Nerquaye-Tetteh (1998) and Nkandawire and Mataya (1985). They observe that one of the problems facing some youth centres in Ghana is the inability of the various stakeholders to follow-up the few cases they have managed to refer to the youth for redress. They therefore called for a concerted effort by all stakeholders including government, nongovernmental organizations and other stakeholders to team up to 
regularly organize workshops for all stakeholders to see the need to follow-up cases they have referred to the centres in the interest of the clients they are serving.

The key issue here apart from other factors discussed earlier in the analysis of stakeholders' role at the youth centre is once again the "need" for the stakeholders to see that following up cases they themselves have referred is mandatory and must be done no matter the cost. Failure to do so is against the principles of guidance and counselling. Guidance helps individuals to know and understand themselves as well as the environment in order to make a judicious decision in life. This requires planned follow-up activities to find out the extent to which clients are responding to issues and changes in life (Gibson and Mitchell, 1990). This certainly requires amendment in the way the stakeholders operate in FLE matters as well as the need for education and basic training for stakeholders on regular sustainable basis. Finally, the weak and nearly non-existent follow-up cases at the centre could be partly responsible for the large number of youth who relapse into nefarious activities after they had already sought guidance and direction at the centre. This development has something to do with lack of support the youth do not get from the adults after the initial direction. The worst cases of youth indiscipline we are witnessing in recent times could be partly attributed to this factor and everything possible must be done to reverse this trend.

Certainly the poor performances of the stakeholders and their effects on the lives of the youth at the centre have implications for counselling. The problem is purely attitudinal and counsellors (PPAG Officials) need to work on the behaviour of the stakeholders for a positive change. This will pave a way for the stakeholders to understand themselves and the environment in which they are working in order to help the youth to make judicious decisions to better their lives (Pecku, 1991).

\section{Implications for Counselling and Administration}

Clearly, the various stakeholders (who are administrators and counsellors by nature of their work) have failed to live up to expectation in almost all the elements or roles they are supposed to play to facilitate the smooth running of the centre. This means that the youth are not enjoying the quality care delivery they are supposed to receive from their mentors thereby leaving them to their fate to fend for themselves. This calls for sustained and long- term programmes if the impact or the effect of stakeholders' roles are to be felt in FLE services for the youth. This means that well programmed educational campaigns should be mounted by the 
centre for all stakeholders on a regular and sustainable basis to achieve this desired goal. Specifically, the stakeholders should see the "need" for these roles to be performed. They should know that the recommendation, information visitation, referral and follow-up roles go together. They are complementary rather than contradictory. Counselling services are clearly an on-going activity. The services must be followed up to the end to make sure that there is a real change in the client. (Pecku, 1992). They should be morally bound to see to the need of their clients. There should be empathic understanding on the part of the stakeholders to resolve the problems of the clients (Okobia, 1992).

The stakeholders should also be aware that in matters like this, commitment counts. Where commitment is paramount, one can even overcome all the obstacles in ones way and even make progress. The commitment level of stakeholders was at its lowest ebb and needs to be gingered. It is a well known fact that in counselling the counsellor is there to render services and to assist the client to resolve his or her problems. It is in this vein that the stakeholders must render genuine services to the clients (Pecku, 1991).

Motivation is a key issue in all human endeavour. While this key factor is absent or minimal the output of service providers also tends to dwindle. The stakeholders are not paid for the services rendered for the youth at the centre. It is purely sacrificial work. The issue of time factor also worsens the situation. The stakeholders are at a loss whether to concentrate on the activities at the youth centre which bring no financial reward or to focus or their formal work which is financially rewarded. This certainly calls for a review of the situation. The stakeholders must at least be recognized. A token of appreciation by way of certificates and plagues or even organizing a durbar in their honour with attended publicity will spur them on to do their best. The PPAG, must, as a matter of policy, empathise with the stakeholders, as demanded by the principles of counselling to work for the benefit of their clients. They must be assisted by government, non-governmental organizations, as well as well meaning individuals (Okobiah, 1992; Olu Makinde, 1983, 1987).

\section{References}

Badu, Gyasi Kwaku (2006), - The perceptions of youth towards ppag family life education programme in Cape Coast. Unpublished (PhD) Thesis Work, University of Cape Coast; Cape Coast. 
Connolly, M (1992). Street kids international karate kids - Reaching the unreached: aids education and prevention. Baltimore, Centre for Communication Programmes.

Davies, R and Houghton P. (1991). Mastering psychology, Macmillan Press Ltd. London.

Fobih, D. K (1993) “Adolescent Students and Their Teachers' Views on Some Social Category Issues: Implications for School Authority and Student Relations" Unpublished Research Work.

Gibson R. L. And Mitchell, M. H. (1990) Introduction to counselling and guidance (211d Ed.), Macmillan Publishing Company, New York.

Glover, E,K, Erulkar, A.S and Nerquaye-Tetteh, J (1998). Youth centres in Ghana: assessment of the PPAG programmes. PPAG, Accra.

Nkadawire, R.M and Matayg, C.S (1985). Youth education and services for health and family Life. International Parenthood Federation. African Region, 34. Okobiah 0. C. (1992). Practicum in counselling: training and supervision. Haliman Publishers, Nsukka, Nigeria.

Okobiah, O. C. (1992). Practicum in counselling: Training and supervision. Haliman Publishers, Nsukka, Nigeria.

Olu Makinde, (1983). Fundamentals of guidance and counselling. Macmillan Publishers.

Olu Malcinde (1987). Guidance principles and services London, Macmillan Co. Pecku, N.K. (1991). Introduction to guidance for training colleges, Ghana University Press, Accra.

Pecku, N. K. (1991). Introduction to guidance for training colleges, Ghana University Press, Accra 